\title{
A Study on the Economic Evaluation for a Feasibility Study in Molybdenum Mineral Processing
}

\author{
Seong-Young $\mathrm{NAM}^{1}$, Jang-Hoon $\mathrm{ROH}^{1}$, Ye-Jin YANG ${ }^{1}$, Nam-Il UM ${ }^{2}$, \\ Ji-Whan $\mathrm{AHN}^{3}$ and Jin $\mathrm{KIM}^{1 *}$ \\ ${ }^{1}$ Department of Energy Resources Engineering, Inha University, Korea \\ ${ }^{2}$ National Institute of Environmental Research, Korea \\ ${ }^{3}$ Korea Institute of Geoscience and Mineral Resources, Korea
}

\begin{abstract}
In the development of mines, risk is latent in a variety of areas. Thus a feasibility study was conducted to determine certain risks. In particular, mineral processing for the recovery of a target mineral constitutes a very large percentage of the cost from the start of a project, and it is an important step in relation to the recovery of funds. In this study, a feasibility study of molybdenum mineral processing is done and comparisons are made between a pilot plant and a commercial plant using the LCCA evaluation method. At the pilot plant, the NPV value of a deterministic approach at five years is $\$ 68,984$ and the probability that the NPV exceeds 0 is $58.23 \%$ according to Monte Carlo simulation done using a probabilistic approach. At the commercial plant, the NPV value with the deterministic approach at five years is $-\$ 10,820,473$, and it was found that the probability of NPV according to deterministic estimation is $49.91 \%$ in a Monte Carlo simulation. As a result, the commercial plant is evaluated as experiencing a loss due to a decrease in the molybdenum concentrate price, whereas a price increase of $20 \%$ relative to the current molybdenum concentrate price can meet the margin after five years when the NPV exceeds over 0 .
\end{abstract}

Key words: Mine development, Mineral Processing, Molybdenum, Feasibility study

\section{Introduction}

In response to rapid changes in mineral price recently, the need for mine redevelopment, active overseas resource development and the redevelopment of abandoned mines as an important issue has been recognized in Korea. In the redevelopment of these mineral resources, metal mines are the main area of focus, and research and technical evaluations of the relevance of projects associated with this effort have advanced steadily ${ }^{1}$. Prior to the development of these mines, a feasibility study may be the most important process for analyzing the relevant economic parameters, as this type of study can provide basic data pertaining to the final development with regard to the technolo-

Paper presented at the $11^{\text {th }}$ Japan/Korea International Symposium on Resources Recycling and Materials Science, 17-19 June 2013, Osaka, Japan

Accepted 10 February, 2014

*e-mail: jinkim@inha.ac.kr gy, environment and market at the time. In other words, a feasibility study is a type of preliminary study related to the optimization of all parameters that affect the success or failure of a project taking into account the production scale, technology level, production costs, sales, and return on investment. Before selecting a project to be carried out, an accurate prediction of the profitability and minimization of the risk of the project must be done. An evaluation of the validity of the development of a mine, to formulate a mine development plan and to evaluate the quality reserves is crucial, and this must be done before data analysis and exploration processes ${ }^{2}$. In addition, the selection of mineral processing and smelting processes must take into account the mass balance, process design, recovery rate and quality of the minerals. In particular, the mineral processing cost to recover a target mineral is a very large percentage of the overall cost during the course of the project, and it is an important step related to the recovery 
of funds.

In Korea, evaluations of validity integrated with a focus on resource development have been carried out by resource development companies, and for the security of most of these companies, these are done in private $^{3}$. On the other hand, in other industries, processes that are commonly used are life-cycle assessment(LCA), life cycle cost analysis(LCCA) and total cost analysis (TCA). These processes, when used properly improve the processing of a product. Evaluation methods suitable for each type of industrial research are commonly and actively done.

As part of the technology development research related to mineral processing, research is advanced at the pilot plant scale and at the lab scale. However, if economic evaluations of the feasibility of each project are not carried out properly, the mineral processing percentage of the actual cost will appear as a very small number in actuality. In a feasibility study of the mineral processing, Kim (1977) considered the economics of the mineral processing of a low-grade mineral ${ }^{4}$, and Oh (1982) examined the economics of the mineral processing of lead and zinc mines ${ }^{5}$. In addition, Yang (2001) presented a case study which examined the economy and exploitation of titanium mineral processing steps ${ }^{6}$, but in a feasibility study, comparisons of costs of the product to be sold and simple economic analyses are performed. Kim (2008) studied the development of an economic evaluation program for feasibility studies, breaking down the borrowing amounts necessary for the development of mines; the sales costs; the selling, general, and administrative expenses; depreciation; and various taxes. In addition, the authors have developed a program that can calculate payback funds and evaluate the economics of such funds given the investment, Internal Rate of Return(IRR) and Net Present Value(NPV) as inputs $^{2}$. This can be done easily considering the financial aspects based on an economic evaluation of the existing characteristics related to mineral processing, though it does not consider the need for a comparative analysis of various processes. Regarding the situation in Korea, economic evaluations with a focus on resource development have been carried out, but an economic evaluation with a focus on mineral processing for the recovery of minerals of interest has not been done, which is why such studies that supply economic assessments are urgent.

In this study, for the purpose of a feasibility study pertaining to mineral processing, and to determine a metal mineral typical in the develop- ment of a metal mine as noted in relation to the active development at present in the country, two different techniques, were applied for an economic evaluation.

\section{Economic evaluation of a feasibility study}

\subsection{Life Cycle Cost Analysis (LCCA)}

Life cycle cost analysis (LCCA) accounts for all of the costs pertaining to the lifecycle, arising in all or parts of the facilities which use a complex industrial process. It is a means of evaluating economic efficiency in relation to public life. As used here, the term "lifecycle" is a term pertaining to the entire process, including the dismantling of production facilities and all other steps, including business planning, design, bidding \& contracting, and pre-construction processes such as demolitions. In order to apply the LCCA evaluation method, it is necessary to consider various factors through different economic approaches to perform a proper economic analysis ${ }^{7}$. The scope of application of various variables is converted appropriately for each project on the basis of basic objective processes, as shown in Fig. 1. With the formulated strategy for the project, and with the help of experienced personnel and experts, we propose a lifecycle strategic potential, a type of LCCA evaluation, and set the content and development goals. This is done based on information collected in an effort to examine whether the probabilistic method and deterministic method approaches can be applied to determine the variables of the LCCA. An expenditure stream will be constructed to determine the analysis period, and discount rates are used as economic variables which recur every year. With variables that have been established through discounted future costs,

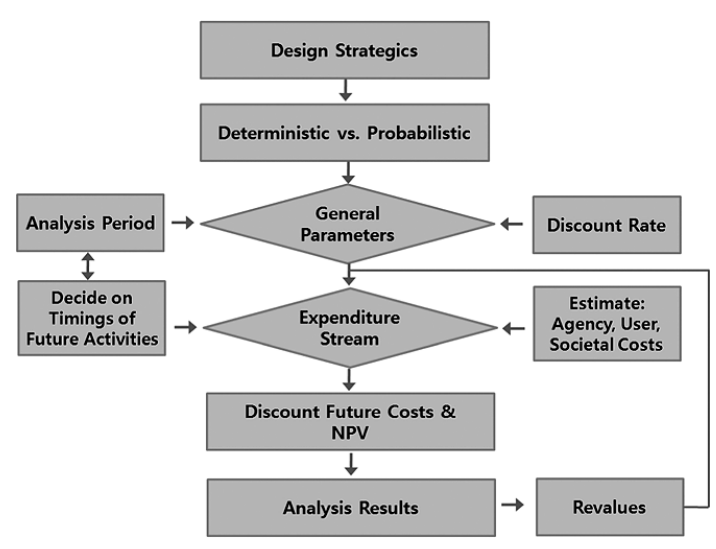

Fig. 1 LCCA Process Flowchart ${ }^{8}$ 
calculated NPV is used to conduct a sensitivity analysis. A revaluing step based on the results of the previous evaluation is performed as part of the feasibility study of the project. In the event of missing or flawed parts, a reevaluation and redefinition of all variables of the project must then be done ${ }^{8}$.

Based on the LCCA method for mineral processing, the results of the preliminary study of the mineral processing technology and the determination of evaluation parameters are required before the next step can be taken. The target mineral is thus selected, applying the LCCA. This economic analysis was done to assist with investment decisions for the business in the future.

\subsection{Deterministic and Probabilistic analysis method}

An economic evaluation for a feasibility study can be done in a variety of ways. Table 1 shows an evaluation method for an economy. The point estimation method is a simple analysis method which relies on the IRR and NPV. It is easy, however, to fall into the trap of averaging, and this method has a drawback in that it ignores interdependencies. An interval estimation method is a sensitivity analysis that makes it possible to calculate the average, minimum, and maximum values of a target. However, it is not possible to obtain the probability of generating a large amount of data, and the selection criteria represent another drawback. On the other hand, a probability estimation method such as Monte Carlo simulation is an extension of the scenario analysis and sensitivity analysis mentioned above. It uses a correlation coefficient and reflects the interdependencies between the variables. The resulting values have the advantage of enabling stochastic decision-making? .
Point estimation, a deterministic analysis method, can be done using a Net Cash Flow (NCF) model regarding the difference in cash outflows related to cash inflows over a period of time. It can be expressed by the equation below.

$$
N C F_{t}=C I_{t}-C O_{t}
$$

The sum of the cash inflow is $\mathrm{CI}_{t}$, the sum of cash outflow is $\mathrm{CO}_{t}$ and $\mathrm{NCF}_{\mathrm{t}}$ is the difference between the cash inflow and outflow, that is, the net cash flow.

In recent economic analyses, this equation is mainly used to consider the discounted cash flow of the time value of money. The discounted cash flow method uses the Net Present Value (NPV), Internal Rate of Return (IRR) and profitability index (PI). By generally applying the concept of the time value of money, the NPV method is widely used by subtracting the outflow of all cash from all expected cash flows, for which discounting the present value is done ${ }^{10}$. This can be expressed by following equation.

$$
N P V=\sum_{t=0}^{\infty}\left[\frac{C I_{t}}{(1+r)^{t}}-\frac{C O_{t}}{(1+r)^{t}}\right]
$$

The sum of the cash inflow is $\mathrm{CI}_{\mathrm{t}}$, the sum of the cash outflow is $\mathrm{CO}_{\mathrm{t}}$ and $\mathrm{r}$ is the discount rate. The NPV is the difference between the present values of the cash outflow and the future value. If the NPV is greater than 0 at that time, the investment plan of this project is adopted. If it is less than 0 , the plan is rejected and reviewed again ${ }^{10}$. However, various parameters have latent risk in economics in these analyzes, and a sensitivity analysis will be carried out after the calculation of

\begin{tabular}{|c|c|c|c|}
\hline & $\begin{array}{l}\text { Point estimation } \\
\text { (e.g., NPV, IRR) }\end{array}$ & $\begin{array}{c}\text { Interval estimation } \\
\text { (e.g., Sensitivity analysis) }\end{array}$ & $\begin{array}{c}\text { Probability estimation } \\
\text { (e.g., Monte Carlo simulation) }\end{array}$ \\
\hline Objects & $\begin{array}{l}\text { Estimation of the mean value } \\
\text { of the single value closest to } \\
\text { the dependent variable }\end{array}$ & $\begin{array}{l}\text { Range estimate of the value of } \\
\text { the dependent variable }\end{array}$ & $\begin{array}{l}\text { Probability estimation of } \\
\text { individual values and the range } \\
\text { of values of the dependent } \\
\text { variable }\end{array}$ \\
\hline Parameters & Average value & $\begin{array}{l}\text { Average value and standard } \\
\text { deviation }\end{array}$ & $\begin{array}{l}\text { Changes in the number of full } \\
\text { distributions and the distribu- } \\
\text { tion of values }\end{array}$ \\
\hline Advantages & Simple calculation & $\begin{array}{l}\text { Full presumed libraries average } \\
\text { value, minimum value, maxi- } \\
\text { mum value may be calculated }\end{array}$ & $\begin{array}{l}\text { Full presumed correct value } \\
\text { rate decisions are possible }\end{array}$ \\
\hline Disadvantages & $\begin{array}{l}\text { Easy to fall into the trap of } \\
\text { averaging }\end{array}$ & $\begin{array}{l}\text { Selection of decision criteria } \\
\text { for the range of values is } \\
\text { difficult }\end{array}$ & $\begin{array}{l}\text { Requires special software or } \\
\text { spreadsheet }\end{array}$ \\
\hline
\end{tabular}

Table 1 Advantages and disadvantages of economic evaluations ${ }^{9}$ 
the feasibility indicators. In general, a sensitivity analysis is a method of analysis that involves changing the value of a variable for which uncertainty is high in the analysis. The effects of this variable on the income and expenses of a business are considerable. With this method, changes in the analysis indicators pertaining to commercial viability can be observed. It involves changing the values while assuming a general, positive and negative situation. The value of the variable is determined with reference to similar cases and experts $^{10,11}$.

However, a sensitivity analysis can confirm a range of predicted values given the size, which is determined to increase or decrease, for each item, either making a decision based on which range of values is derived, though this is difficult. It follows that carrying out a probabilistic analysis is necessary in order to supplement this method. The probability analysis method uses a probability model; the Monte Carlo simulation is a typical technique. When the distribution of the variables is given, randomly hundreds of times or thousands of times this process is run to generate a random number arbitrarily in accordance with the distribution. The Monte Carlo simulation predicts the values of the results in the model as determined based on random numbers by repeating the runs several times per process to derive an overall probability distribution of the resulting value which was to be predicted. Therefore, it is done to derive the distribution of the determined value rather than its determined value and thus to support decision-making and decision makers. Fig. 2 represents the probability distribution of the input variables that are commonly used in Monte Carlo simulations. The results are not determined value

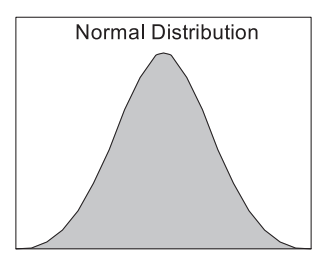

Normal distribution

Uniform Distribution

Uniform distribution

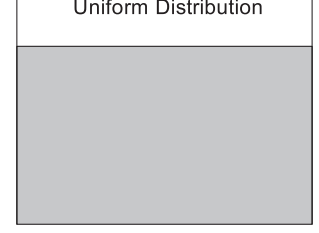

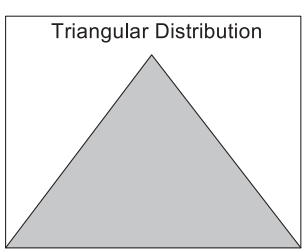

Triangular distribution

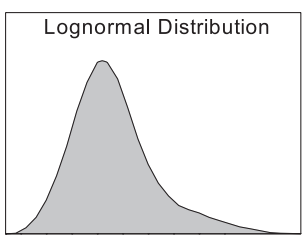

Log-normal distribution
Fig. 2 Probability distributions of the input variables ${ }^{12}$ by one input variable but are determined by a specific distributed distribution with respect to the uncertainty of each variable. The normal distribution, the probability that a particular value of a variable typically occurs, is the largest, and it is used when the average value of the distribution is known. A triangle distribution is used when the maximum, minimum and mode values are known. A uniform distribution is used when the probabilities that the value of the range of the maximum value and the minimum value generated is identical. A log-normal distribution is a distribution that is used if blur is associated with a positive value ${ }^{12}$.

\section{Results and Discussion}

\subsection{Selecting the target mineral for a feasibility study}

For an economic evaluation for a feasibility study related to mineral processing, the current state of domestic metal mines was examined. In Korea, the reserves of metal minerals except anthracite and uranium minerals totaled 130 million tons, only $0.8 \%$ of the reserves of mineral resources. Domestic metal mines are determined, as there is a possibility of the development of molybdenum, copper, and tungsten but not gold or iron ore. Recently, metal mines such as the NMC molybdenum mine (molybdenum), the Dongbo mine (tungsten), and the Gagok mine (zinc) are being actively developed. In particular, the NMC molybdenum mine, which is located in Jecheon, Chungbuk, produces 360,000 tons of molybdenum ore per year through a systematic process of crushing and mineral processing. Molybdenum is produced actively; for this reason, it is selected as the target mineral for a feasibility study. A comparative analysis of a pilot plant and a commercial plant for molybdenum was carried out.

A large-scale surface mining method is used to obtain large quantities of low-grade molybdenum at a low cost. For underground mining, a block caving method is normally used to obtain highgrade molybdenum. The diameter of the molybdenum ore reaches that of micron particles $(1 \mu \mathrm{m})$, and it is liberated from the host rock while passing through a grinding process, which can be a ball-mill or rod-mill process. After pulverizing the ore, flotation is used while adding collectors to the ore slurry. Through the flotation process, the molybdenum particles are given hydrophobic properties and air is then injected to make this hydrophobic molybdenite slurry float. These floating materials are recovered, which increases the percentage of the molybdenite in the concentrate. 
The final concentrate includes approximately $60 \%$ molybdenite. If necessary, a smelting process is used to remove impurities such as copper and zinc ${ }^{1}$. 3.2 Deriving the parameters for a feasibility study in molybdenum mineral processing

The aim of mineral processing is significantly divided into technical and economic objectives. The main objective of the technical aspects is to recover a large amount of pure target materials to the greatest extent possible. The main economic objective is to maximize the margin between the revenue obtained by selling the target mineral and the recovery cost. To evaluate the economic validity of mineral processing, these two purposes should be optimized. Major issues that should be considered in the optimization process are selecting the mineral process and the smelting method, recovery rate, standard of the final product, the pilot test, and the plant design. A number of variables are considered together with this issue. The standards of the office equipment and devices used in molybdenum mineral processing, the construction costs, and the operation items are set, and each parameter is measured for the evaluation. Because the equipment that is used in mineral processing is differentiated in terms of the scale and characteristics of each piece, the process should be designed depending on the capacities. The equipment for the pilot plant (5 tons per hour) is shown below.

\section{- Jaw Crusher \\ - Roll Crusher \\ - Vibrating Screen \\ - Flotation}

The equipment for the commercial plant (50 tons per hour) is shown below.

$\begin{array}{ll}\text { - Jaw Crusher } & \text { - Cone Crusher } \\ \text { - Vibrating Screen } & \text { - Conveyor Belt } \\ \text { - Ore Bin } & \text { - Ball Mill } \\ \text { - Spiral Classifier } & \text { - Cyclone } \\ \text { - Flotation devices } & \text { - Dehydration }\end{array}$

In addition to the plant equipment, other devices used in offices for workers include the following items.

\section{- Computers \\ - Telephones \\ - Copiers \\ - Fax Machines \\ - Computer Printers • Air Conditioners \\ - Furniture (Desks \& Chairs)}

The civil engineering construction costs for in- stalling equipment for mineral processing, and the structural construction costs for installing the primary equipment fall in the category of the initial investment. In general, the transportation cost decreases as the mineral processing facilities are located close to the mine. Therefore, it is assumed that the facilities are set in the mine. Thus, the use of land parameters corresponding to these facilities will not be considered. In addition, the installation of the plant was not considered, as mineral processing can be operated outdoors. Moreover, the costs of office buildings for production workers and site management are included in the parameters. The costs of the construction of waste rock piles to store mining waste from the mineral processing activities and wastewater treatment facilities to treat the wastewater generated during the flotation process are included. These parameters are as follows:

- Civil engineering

- Structure constructions

- Waste rock pile

- Construction (office)

- Wastewater treatment facilities

In order to operate mineral processing facilities, a variety of parameters should be considered. The annual cost parameters are as follows:

$\begin{array}{ll}\text { - Molybdenum Ore } & \text { - Flotation agents } \\ \text { - Water } & \text { - Electrical power } \\ \text { - Wastewater treatment } & \\ \text { - Mining waste } & \text { - Labor costs } \\ \text { - Indirect costs } & \text { - Depreciation costs } \\ \text { - Others (maintenance, taxes, insurance etc.) }\end{array}$

As parameters for the flotation process, $\mathrm{Na}_{2} \mathrm{SiO}_{3}$ is used to suppress silicate minerals, kerosene is used as a collector, and pine oil is used as a forming agent. Also, a certain amount of water is required; thus, wastewater and mine waste are generated. Power consumption by each piece of equipment related to the mineral processing activities differs. In particular, the crushing process consumes most of the electrical power. The other operating costs, such as the labor costs, indirect costs, maintenance costs, taxes, and depreciation costs, are considered in the feasibility study.

3.3 Feasibility study of molybdenum mineral processing with a deterministic analysis

A feasibility study of molybdenum mineral processing was done for a pilot plant based on the technical development results by $\operatorname{Kim}(2009)^{1}$. Table 2 shows the intended ore input and concen- 
Table 2 Mass Balance of Molybdenum Mineral Processing of the Pilot Plant

\begin{tabular}{ll}
\hline \multicolumn{1}{c}{ Scale } & \multicolumn{1}{c}{$\begin{array}{c}5 \text { tons/hour, } 8 \text { hours/day, } \\
\text { 300 days/year }\end{array}$} \\
\hline Molybdenum Ore & 12,000 tons/year $(0.81 \% \mathrm{Mo})$ \\
\hline Concentrate & $\begin{array}{l}89.7 \text { tons/year } \\
\text { Production }\end{array}$ \\
\hline Mine Waste & 11910.3 Mo, $92.3 \%$ of recovery $)$ \\
\hline Waste Water & 360,000 tons/year \\
\hline
\end{tabular}

trated output at five tons/hour, at a recovery rate of $92.3 \%$ and with molybdenum concentrate accounting for $54.5 \%$ of the products. Therefore, 12,000 tons of molybdenum ore become 89.7 tons of molybdenum concentrate per year. The molybdenum concentrate grade of $54.5 \%$ is very high considering that mineral processing produces molybdenum concentrate of a high quality.

A feasibility study of molybdenum mineral processing of commercial plant was done based on a commercial production company in Korea. Table 3 shows the intended ore input and concentrate output of 50 tons/hour, with a recovery rate of $95.0 \%$ and with molybdenum concentrate of $51.0 \%$ of the products. Therefore, 360,000 tons of molybdenum ore becomes 1,026 tons of molybdenum concentrate per year. Commercial plants use
Table 3 Mass Balance of Molybdenum Mineral Processing at the Commercial Plant

\begin{tabular}{ll}
\hline \multicolumn{1}{c}{ Scale } & \multicolumn{1}{c}{$\begin{array}{c}50 \text { tons/hour, } 24 \text { hours/day, } \\
\text { 300 days/year }\end{array}$} \\
\hline Molybdenum Ore & 360,000 tons/year $(0.30 \% \mathrm{Mo})$ \\
\hline $\begin{array}{l}\text { Concentrate } \\
\text { Production }\end{array}$ & $\begin{array}{l}1,026 \text { tons/year } \\
(51.0 \% \mathrm{Mo}, 95.0 \% \text { of recovery })\end{array}$ \\
\hline Mine Waste & 358,974 tons/year \\
\hline Waste Water & $1,080,000$ tons/year \\
\hline
\end{tabular}

fewer products than the pilot plant for the purpose of this study, and the quality of the ore used is $0.30 \%$. The quality of the concentrate produced is $51.0 \%$. It was determined that $51.0 \%$ of the molybdenum concentrate is commercially for products. A technical process was used for highquality production at the pilot plant and an economical process was used at the commercial plant.

As shown in Fig. 3(a), molybdenum mineral processing at pilot plant is carried out, involving crushing, grinding, primary and secondary flotation. The main equipment is a jaw crusher for crushing, a cone crusher for pulverizing, after which the mineral is ground into fine particles in a rod mill. It is possible to produce concentrated product via primary flotation and secondary flotation.

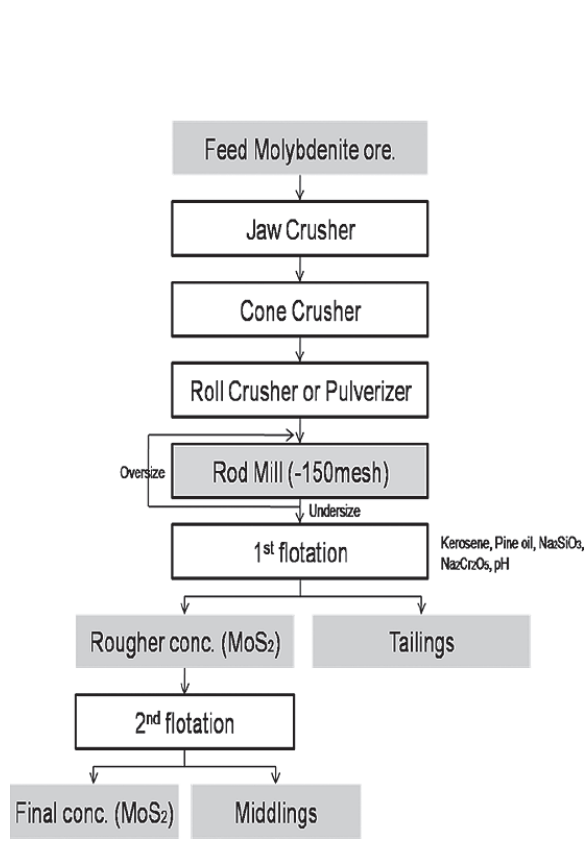

a) Pilot plant
Crushing Process (170 ton/hr)
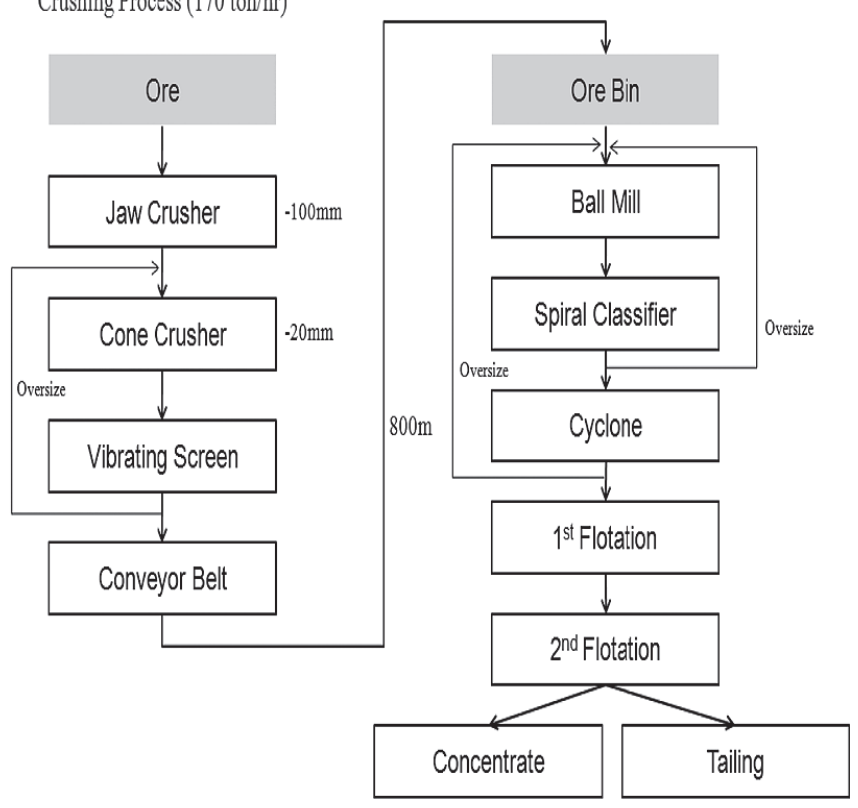

b) Commercial plant

Fig. 3 Flow sheet for mineral processing of molybdenite minerals 
NAM, ROH, YANG, UM, AHN and KIM

Table 4 Net Cash Flow (NCF)

\begin{tabular}{lrrrrr}
\hline \multicolumn{1}{c}{ Pilot-plant } & & & \multicolumn{2}{c}{ Commercial-plant } \\
\cline { 1 - 2 } \cline { 5 - 6 } Content & Price $(\$)$ & & \multicolumn{2}{c}{ Content } & Price $(\$)$ \\
\hline Initial Investment & $1,226,200$ & & Initial Investment & $12,698,500$ \\
\hline Annual Operating Cost & 914,925 & & Annual Operating Cost & $13,868,581$ \\
\hline Annual Sales & $1,255,800$ & & Annual Sales & $14,364,000$ \\
\hline NCF at 1 year & $-885,325$ & & NCF at 1 years & $-12,203,081$ \\
\hline
\end{tabular}

As shown in Fig. 3(b), molybdenum mineral processing is carried out at the commercial plant via crushing, grinding, and flotation. During the crushing process, 170 tons/hour and 1,360 tons/ day are processes for 8 hours. The main equipment includes a jaw crusher, a cone crusher, a vibrating screen and a conveyor belt. Crushed ore is transferred to an ore bin for storage through an $800 \mathrm{~m}$ conveyor belt and after the grinding and mineral processing steps. During the grinding and mineral processing steps, 50 tons/hour and 1,200 tons/day for 24 hours are processes. The main equipment includes a ball mill, a spiral classifier, a cyclone, and primary and secondary flotation devices.

The initial investment must consider the size and characteristics of the pilot plant and the commercial plant. Regarding the price of the equipment, calculating the total purchasing cost of the equipment is done. It is also necessary to calculate the costs for installation, transportation, installation labor, installation overhead, and for a reserve fund for equipment. The amount of initial investment at the pilot plant was calculated as $\$ 1,226,200$, and the value was $\$ 12,698,500$ for the commercial plant. The total annual expenditure cost for the production of molybdenum concentrate was calculated, including the ore costs, operating costs, indirect costs, labor costs, depreciation costs and other costs. The molybdenum ore costs are calculated based on the trading price on the London Metal Exchange (LME) in 2013; the total annual production cost of the pilot plant is $\$ 914,925$, while it is $\$ 13,868,581$ at the commercial plant. In terms of annual sales of molybdenum concentrate, the pilot plant sells $\$ 1,255,800$ and the commercial plant sells $\$ 14,364,000$ based on the trading price of the LME in 2013. An economic evaluation was carried out to assess the validity basis of the sales of the molybdenum concentrate, and the expenditure is the sum of the annual operating costs and initial investment cost. As shown in Table 4, the results use the net cash flow (NCF). The price of commercial plant was almost 10 times higher than the price of pilot plant because the scale of the mineral processing is increased, the price of initial investment and operating cost is increased.

Molybdenum mineral processing at the pilot plant was calculated to be $-\$ 885,325$ for the NCF for one year, showing a loss because it took into account the initial investment. However, the loss of cost is expected to decline with annual production sales. For the NCF over the next ten years, the net income is expected to exceed the breakeven point from four years after the initial year. On the other hand, molybdenum mineral processing at the commercial plant was calculated as $-\$ 12,203,081$ for the NCF for one year, showing cash flow that is very low. The price of molybdenum concentrate increases to $\$ 35$ at the development time, but this occurs because the current price fell to $\$ 10$. The NCF method has a disadvantage in that does not take into account the time value of the future cost. For this reason, using the net present value (NPV), the adequacy of cash flows was evaluated over the next ten years. In this study, this was calculated by taking into account the $10 \%$ discount rate used in general resource development practices. Fig. 4 shows the NCF and NPV results over the next ten years.

When considering the discount rate, it can be seen that to derive different results from the NCF, the results of the NPV show the net income over the next five years at the pilot plant. Regarding the decision to adopt investment through NCF, it can lead to a judgment showing that it is possible to invest in a short period of five years, with the results of the NPV showing a long-term investment for a period of ten years. The cash flow of molybdenum mineral processing at the commercial plant cannot obtain a return on investment over the next ten years owing to over-spending of the initial investment costs. However, a different result is generated by increasing the molybdenum concentrate price, but if the price does not increase, investment is determined to be impossible at the present time.

As a result, as an index to facilitate the decisionmaking for an owner, adoption of the investment 
a) Pilot plant

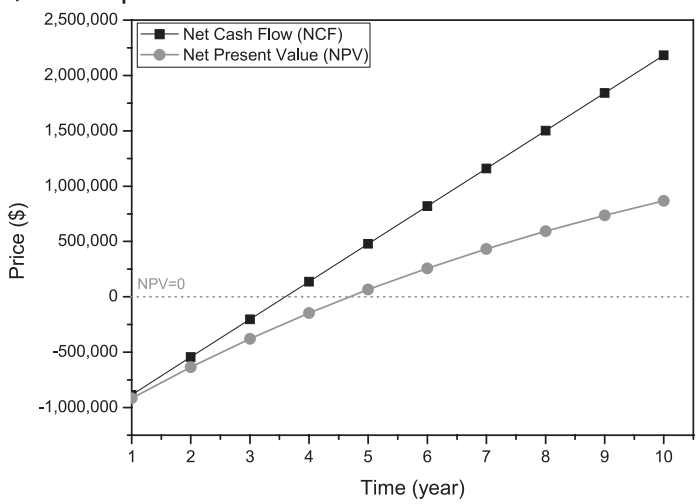

b) Commercial plant

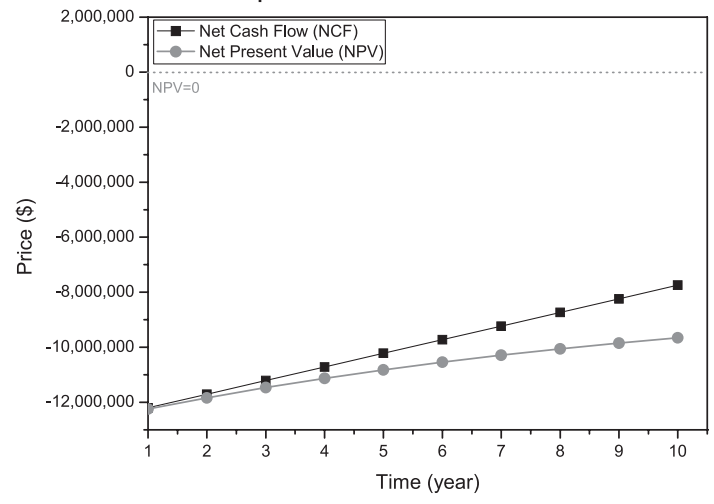

Fig. 4 Results of the NCF and NPV over the next ten years

will be left to the discretion of the owner. However, the various risks cannot be determined by a deterministic analysis, and after the calculation of the business analysis indicators, an additional analysis is required, such as a probabilistic analysis.

\subsection{Feasibility study of molybdenum mineral processing with a probabilistic approach}

A Monte Carlo simulation was used as a probabilistic approach for the feasibility study of molybdenum mineral processing. The distribution of the uncertainty variables, their characteristic values and the standard deviation corresponding to the average value were determined. For the cost of raw materials and the product sales, normal distributions were applied. For the initial investment, process operating costs, and labor costs, log-normal distributions were used by applying the rate of price changes.

Fig. 5(a) shows a graph of 10,000 simulations as the cumulative probability results of the NPV estimate in five years according to the Monte Carlo simulation of the pilot plant. The average NPV value is $\$ 68,518$ and the probability that the
NPV exceeds 0 is $58.23 \%$. A probabilistic approach through a Monte Carlo simulation allows various analyses before making a decision. Through a deterministic approach, only a single estimate value was derived, showing that the NPV is $\$ 65,984$. However, through the simulation results, the NPV value and the probability value pertaining to NPV can be derived. It was found that the NPV value according to the probabilistic approach is higher than that by the deterministic approach. It was also found that the probability that the NPV is less than 0 is $41.77 \%$. Even if the resulting value of the NPV through the point estimate approach is greater than 0 as compared to the deterministic approach, a reciprocal conclusion, i.e., that the probability that the NPV is less than 0 is $41.77 \%$, can stop the progress of the project.

Fig. 5(b) shows a graph of 10,000 simulations, showing the cumulative probability results of the NPV estimate in five years year through the Monte Carlo simulation of the commercial plant. There is difference in the NPVs; the NPV value by the deterministic approach is $-\$ 10,820,473$ and the average value of the NPV is $-\$ 10,849,784$ through the probabilistic approach. Therefore, this result is not sufficient for evaluating the economic validity of a project by means of a feasibility study with the value of the NPV through the deterministic approach alone. It was also found that the probability of the NPV according to the deterministic estimation is $49.91 \%$ through the Monte Carlo simulation method.

As shown in Fig. 6(a), regarding the result of the sensitivity analysis using the Monte Carlo simulation at pilot plant, the molybdenum concentrate price has a decisive influence on the NPV at a value of $95.5 \%$. In addition, the initial investment costs of $3.2 \%$, the molybdenum ore costs of $0.7 \%$, the operation costs of $0.5 \%$, and the labor costs of $0.1 \%$ all influence the NPV. As shown in Fig. 6(b), concerning a result of the sensitivity analysis using the Monte Carlo simulation at commercial plant, the molybdenum concentrate price has a decisive influence on the NPV, with a value of $91.5 \%$. In addition, molybdenum ore costs of $5.5 \%$, the initial investment costs of $2.2 \%$, and the operation costs of $0.7 \%$, all influence the NPV. The molybdenum concentrate price has been considered as a very important factor in mineral processing and that is only one factor in cash inflow.

\subsection{Feasibility study according to a change in the molybdenum price}

In the results of the feasibility study of molybdenum mineral processing for the commercial 

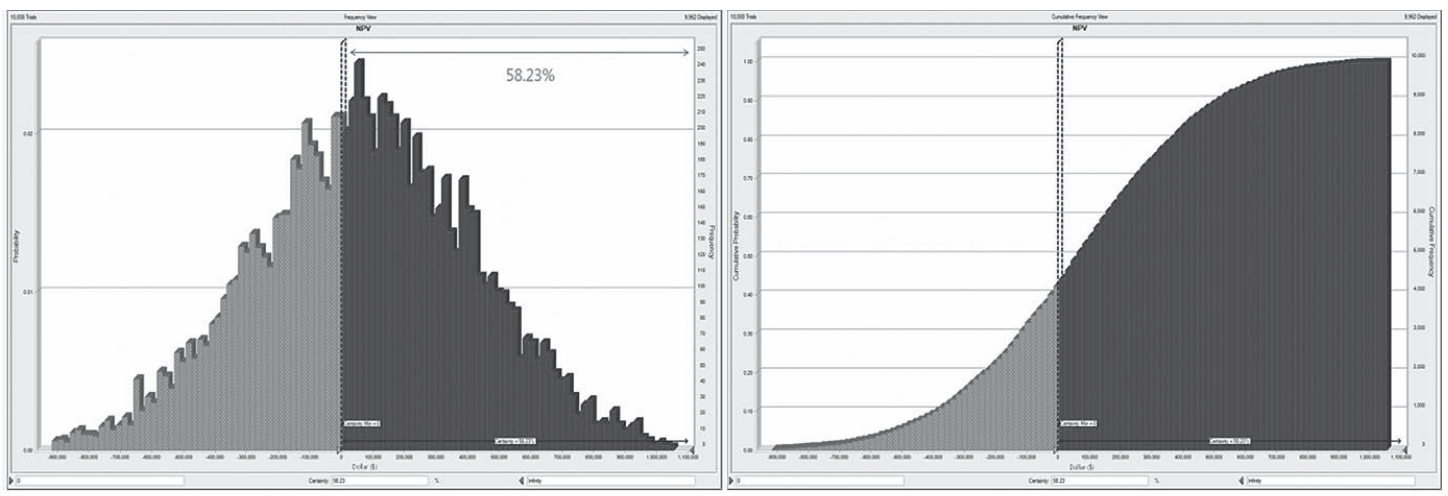

a) Pilot plant

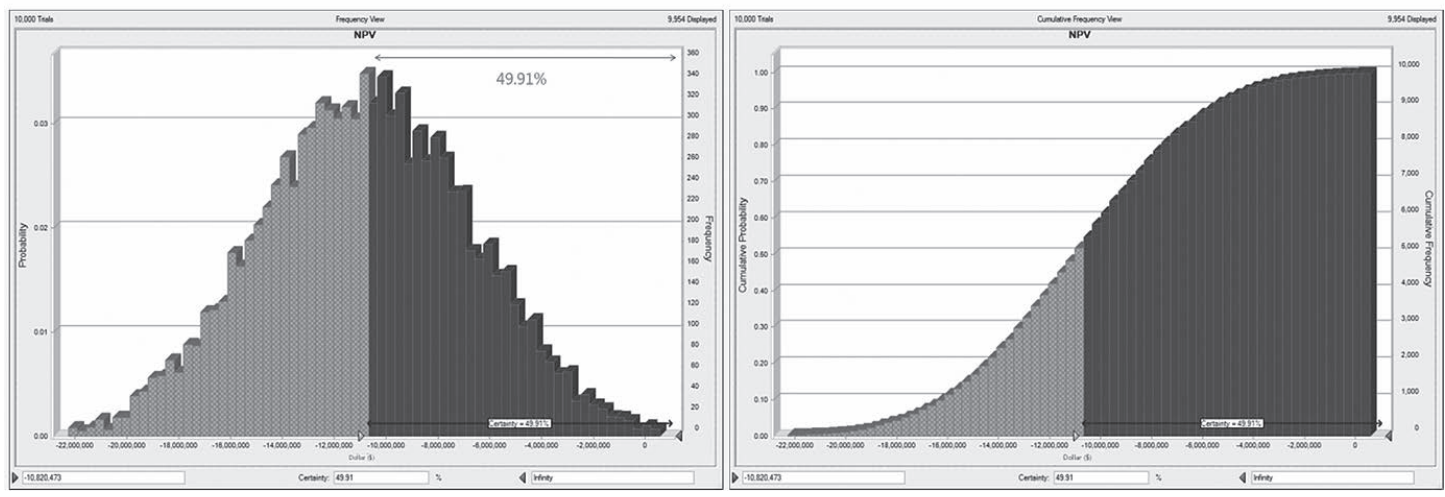

b) Commercial plant

Fig. 5 NPV at five years according to the Monte Carlo simulation

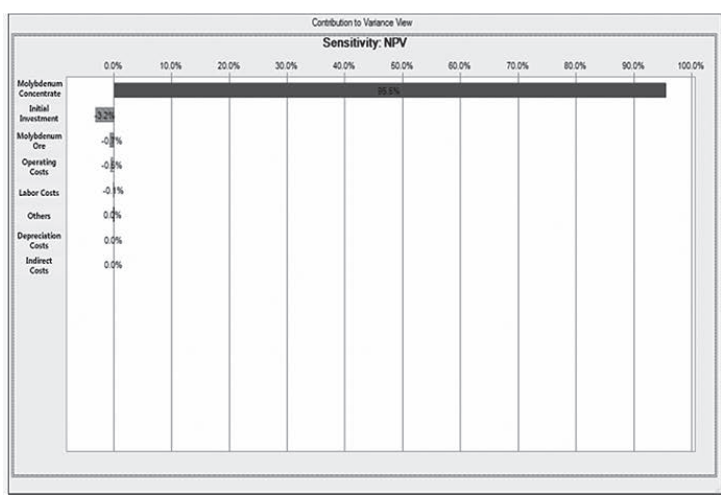

a) Pilot plant

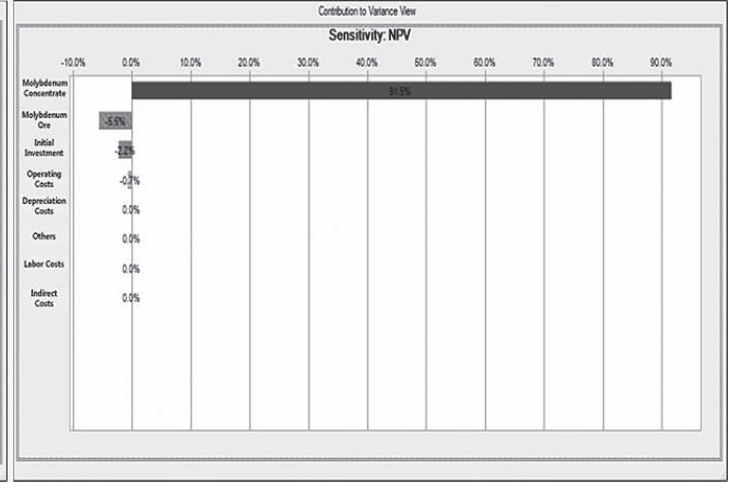

b) Commercial plant

Fig. 6 Sensitivity analysis at five years using the Monte Carlo simulation

plant, if the current price of molybdenum concentrate does not rise, a deficit is expected over the next ten years. However, the price of minerals, including molybdenum, can dramatically change due to a variety of external factors and in a range of mineral industries. As shown in Fig. 7, the price of molybdenum has changed greatly since 2003; the lowest price is approximately $5 \mathrm{USD} / \mathrm{lb}$ 


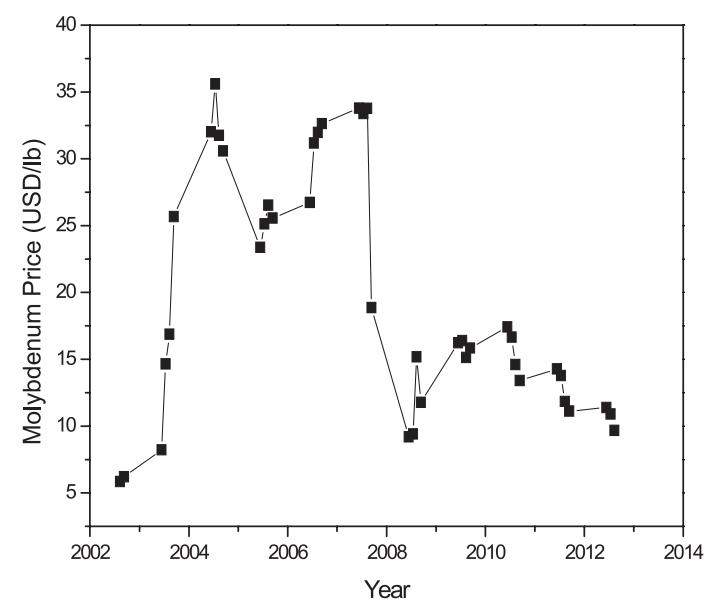

Fig. 7 Molybdenum price (USD/lb) $)^{13}$

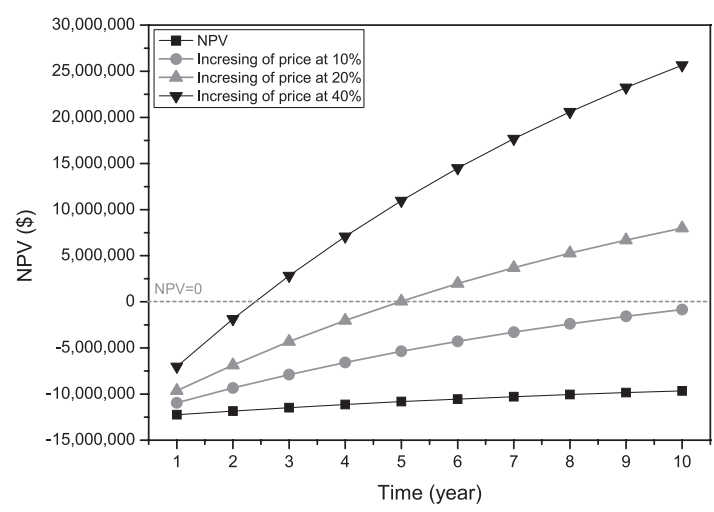

Fig. 8 NPV of molybdenum mineral processing according to an increase in the price

and the maximum is about $35 \mathrm{USD} / \mathrm{lb}^{13}$. Thus, large changes in concentrate prices are expected in the future, and a feasibility study based on this was performed at the time when net income is realized.

Fig. 8 shows the NPV as a result of the molybdenum concentrate price increases at the commercial plant, showing that a price increase of $10 \%$ of the current molybdenum price cannot lead to positive net income over the next ten years. However, a price increase of $20 \%$ of the current molybdenum price can lead to a margin after five years when the NPV exceeds 0 , and if the price increase is $40 \%$ of the current price, the margin is realized after about 2.5 years. Thus, a change in the molybdenum concentrate price is a very important parameter in the feasibility study, and it is necessary to observe price changes and recognize this factor as a risk factor.

\section{Conclusions}

In this study, a LCCA analysis was performed as part of a mineral processing feasibility study related to molybdenum mining. The subject matter for the validity assessment data was evaluated to calculate the design of the process, the material balance, the recovery rate, the initial investment cost of the equipment, and the power consumption. Feasibility results of molybdenum mineral processing were analyzed and compared. The pilot plant assumed at five tons/hour and the commercial plant assumed at 50 tons/hour. At the pilot plant, $\$ 1,226,200$ was determined to be the initial investment cost, and the total annual operating cost was $\$ 914,925$. The result on the basis of the sales revenue of the product per year was $\$ 1,255,800$; the NCF was calculated as $-\$ 885,325$ at one year and $\$ 65,984$ at five years. Through the Monte Carlo simulation, the average value of the NPV is $\$ 68,518$ and the probability of that NPV exceeds 0 is $58.23 \%$ at five years. At the commercial plant, $\$ 12,698,500$ was determined to be the initial investment cost and the total annual operating costs were $\$ 13,868,581$. The result on the basis of the sales revenue of the product per year was $\$ 14,364,000$; the $\mathrm{NCF}$ is calculated as $-\$ 12,203,081$ at one year and $-\$ 10,820,473$ at five years. Through a Monte Carlo simulation, the average value of the NPV is $-\$ 10,849,784$. This is not sufficient for evaluating the economic validity of a project in a feasibility study with the value of the NPV through a deterministic approach only. It was found that the probability of the NPV via a deterministic estimation is $49.91 \%$ through the Monte Carlo simulation. In the results of the feasibility study of molybdenum mineral processing at a commercial plant, if the current price of molybdenum concentrate does not rise, a deficit is expected over the next ten years. However, a price increase of $20 \%$ of the current molybdenum price can realize a margin after five years when the NPV exceeds 0 , and if the price increase is $40 \%$ of the current price, the margin occurs after about 2.5 years. Thus, a change of the molybdenum concentrate price is a very important parameter in a feasibility study, and it is essential to observe price changes and recognize this factor as a risk factor.

\section{Acknowledgment}

This research was supported by a grant (2013) from the Energy Technology Development Program (2013T100100021) funded by the Ministry 
of Trade, Industrial and Energy of the Korean government.

\section{References}

1. S.B. Kim: A study on the utilization technologies for the development of overseas metallic mineral: Report, Ministry of Trade, Industry \& Energy, GP2009-001 (2009)

2. B.C. Kim: The cooperative researches for oversea mineral resources and construction of geoinformation system: Report, Ministry of Trade, Industry \& Energy, NP2007-009-02-2008 (2008)

3. S.B. Jung: Development of technology to recover the valuable resources from abandoned mine; Feasibility study to recover the valuable resources from domestic abandoned mine: Report, Ministry of Trade, Industry \& Energy, 2003-R-RR11-P-012-100-2006 (2007)

4. Y.S. Kim and M.G. Park: Study of economics research on mineral processing of low-grade serpentinite and continuous flotation: The Korean society of mineral and energy Resources Engineers, 14(2), pp. 117-122 (1977)

5. M.S. Oh: A feasibility study in the point of mineral economics, Mining plan and ore dressing: Report,
Korea Institute of Energy and Resources, GOVP1199405548 (1982)

6. J.I. Yang: Studies on mineral processing of ilmenite ore in hadong area and its economical evaluation: Report, Ministry of Trade, Industry \& Energy, GOVP1200107125 (2001)

7. K.F. Sieglinde and R.P. Stephen: Life-Cycle Costing Manual for the Federal Energy Management Program: U.S. Department of Commerce (1996)

8. O. Kaan, A.P. Neville, J. Dima, H. Sajjad: Guidelines for Life Cycle Cost Analysis: U.S. Department of Transportation (2003)

9. H.S. Lee and J.S. Park: Analysis of the validity of the business utilizing the probabilistic model, Caleb Management Review, 2, pp. 20-33 (2009)

10. Y.G. Choi: Economic analysis on utilization technology of molten slag from incineration ash: INHA university, Korea (2005)

11. S.J. Ahn: Stochastic analysis for uncertainty of life cycle assessment with Monte-Carlo simulation: AJOU university, Korea (2005)

12. M. Johnathan: Applied risk analysis; Modeling of spread sheet and crystal ball: Book of Eretec (2005)

13. London Metal Exchange: Molybdenum price in 2003-2013: www.lme.com 